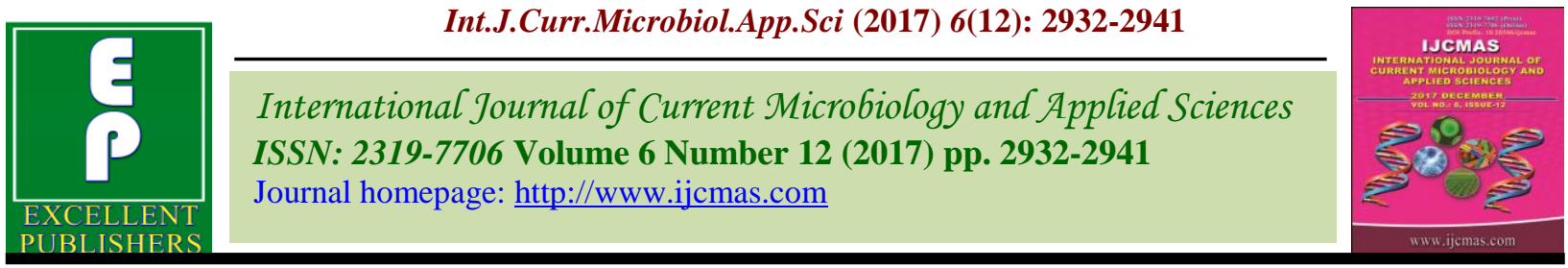

Review Article

https://doi.org/10.20546/ijcmas.2017.612.341

\title{
Nutrient Mining by Selected Cereal Crops and Strategies to Sustain Soil Productivity
}

\author{
C.M. Mamathashree*, S.M. Shilpha and Pradeep
}

Department of Agronomy, UAHS Shivamogga, Karnataka, India

*Corresponding author

\begin{tabular}{|c|c|}
\hline \multicolumn{2}{|r|}{ A B S T R A C T } \\
\hline & \multirow{5}{*}{$\begin{array}{l}\text { Maintenance of native soil fertility in the intensively cultivated regions of the country is } \\
\text { one of the preconditions of maintaining and improving the current crop yield levels. } \\
\text { Intensive cropping systems remove substantial quantities of plant nutrients from soil } \\
\text { during continued agricultural production round the year. The basic principle of } \\
\text { maintaining the fertility status of a soil under high intensity crop production systems is to } \\
\text { annually replenish those nutrients that are removed from the field. Indeed this becomes } \\
\text { more relevant in the absence of the measures for adequate replenishment of the depleted } \\
\text { nutrient pools through the removal of crop residues from agricultural fields (Sanyal, 2014). } \\
\text { Nutrient mining causes a decline in the native soil fertility and may seriously jeopardize } \\
\text { future food security of the country. Unfortunately, the concern for nutrient mining in } \\
\text { Indian soils is largely limited to the scientific community and has not been integrated } \\
\text { adequately with the crop production practices. One would use the term "Nutrient Mining" } \\
\text { when the quantity of soil nutrients removed by a crop from an agricultural field exceeds } \\
\text { the amount of the nutrient that is recycled back and/ or replenished to the field. }\end{array}$} \\
\hline $\begin{array}{l}\text { Ke y w o r d s } \\
\text { Nutrient mining, } \\
\text { Cereal crops, } \\
\text { Productivity. } \\
\end{array}$ & \\
\hline Artic & \\
\hline $\begin{array}{l}\text { Accepted: } \\
21 \text { October } \\
\text { Available } \\
10 \text { Decemb }\end{array}$ & \\
\hline & \\
\hline
\end{tabular}

\section{Introduction}

The nutrient mining issues concern the nutrients that are less mobile in soils and have higher potential of staying in the soil. For example, nitrogen $(\mathrm{N})$ is highly mobile in the soil and has the highest probability, among the major nutrients, to be lost from the soil system through volatilization and leaching, among others. The Indian soils, being in the sub-tropical region coupled with the preponderance of tillage practices, are rarely sufficient in N. Nitrogen is generally applied in adequate quantities to the crops, and "nitrogen mining" is not frequently discussed as crop production relies more on adequate external application through fertilizer/manure sources rather than on the native soil reserve of N. The input-output balance calculations for $\mathrm{N}$, at the regional or the national scale, generally show positive balance in soils (Katyal, 2001). Phosphorus (P) and potassium $(\mathrm{K})$, on the other hand, have lower potential for loss from the soil than N. Except erosion (P) and leaching $(\mathrm{K})$, the extent of loss by other means is negligible for these two nutrients. Phosphorus, by virtue of fixation through the $\mathrm{pH}$-dependent processes, is relatively immobile in soils and excess application of $\mathrm{P}$ through fertilizer may lead to $\mathrm{P}$ build-up in soils. Immediate availability of such fixed $\mathrm{P}$ to the plant is limited, but nonetheless it provides a source of slow supply of $\mathrm{P}$ in the long-term. Some 
assessments, based on total inputs and outputs, have shown a positive balance of $\mathrm{P}$ in Indian soils

\section{Mechanism of nutrient uptake}

Nutrients reach the roots by three mechanisms

\section{Diffusion}

Movement response to concentration gradient (Ca, $\mathrm{Mg}$ and anions).

\section{Mass flow}

Movement with water flow (Dominant for $\mathrm{K}$ and $\mathrm{P}$ )

\section{Root interception}

Root extension to find out new nutrient sources.

\section{Subba Rao and Srivastava (2007)}

Green revolution helped in achieving higher yields but led to nutrient mining hence the multi nutrient deficiencies. This graph is generated by farmer director of Indian society of soil science Srinivas and srivast in this graph we can clearly see that earlier in 1950 only one element $\mathrm{N}$ was deficient in Indian soil. After words for every 10 years more number of beneficial showed the deficiencies in Indian soil. Coming to era of green revolution 1970-1980 we can see that more number of nutrients are deficient because mainly due to introduction of high yielding verities these verities mined the more nutrients from the soil number of elements deficiency was increased at present 2017 8-9 essential elements are deficient in Indian soils. By 2025 some other essential elements may show deficient in Indian soils this may leads to severe decrease in food production and it affects the growing population in India

\section{What is nutrient mining?}

Nutrient mining generally refers to agricultural practices resulting in a negative nutrient balance: export (loss) of a nutrient is greater than import (input). When the quantity of soil nutrients removed by a crop from agricultural field exceeds the amount of nutrient that is recycled back and / or replenished to the field.

This graph shoes the response ratio per applied NPK earlier in 1970 response ratio is very high that is $13.4 \mathrm{~kg}$ grains $/ \mathrm{kg}$ of NPK and it gradually decreases 13.4 to $3.7 \mathrm{~kg}$ grain/NPK in the year it may decreased to 1.5 $\mathrm{kg}$ grain $/ \mathrm{kg}$ of NPK. Decrease in production of Indian agriculture and it affects the growing population in India.

These are all inputs added to soils nutrient added to soil output nutrient removed from the soil mineral fertilizers -added like N P K adds the adequate quantity of nutrient to the soil.

Organic manures-Like compost FYM Green manure upon decomposition adds subsequent amount of nutrient $\mathrm{N}$ to soil. Atmospheric deposition-BNF micro-organisms azospirilum, rhizobium fix atmospheric $\mathrm{N}$ to the soil adds nutrient to the soil. Sedimentation-Weathering of rocks and mineral and by the process of mineralized nutrients coming to the soil solution.

Output Harvested crop part crop residues contains more amount of nutrients grains and Stover its not an actual loses but it is losses to the soil Gaseous losses-Ammonia volatilization and denitrification water erosion-it is not an loss of only soil top soil contains more of nutrients also loss from the Soil. More of nutrient removed from the soil very less quantity of nutrient added to soil it leads to nutrient mining. 


\section{Causes of nutrient mining}

Soil erosion

Skewed nutrient addition

Improper nutrient ratios

Nutrient losses - leaching, volatilization

Nutrient deficiency

Poor organic matter

Inappropriate cultivation practices

\section{Soil erosion}

It is the displacement of upper layer of soil, one form of soil degradation. The erosion of soil is a naturally occurring process on all land. The agents of soil erosion are water and wind, each contributing a significant amount of soil loss each year. Soil erosion may be a slow process that continues relatively unnoticed, or it may occur at an alarming rate causing a serious loss of topsoil. The loss of soil from farmland may be reflected in reduced crop production potential, lower surface water quality and damaged drainage networks.

While erosion is a natural process, human activities have increased by $10-40$ times the rate at which erosion is occurring globally. Excessive (or accelerated) erosion causes both "on-site" and "off-site" problems. On-site impacts include decreases in agricultural productivity and (on natural landscapes) ecological collapse, both because of loss of the nutrient-rich upper soil layers. In some cases, the eventual end result is desertification. Off-site effects include sedimentation of waterways and eutrophication of water bodies, as well as sediment-related damage to roads and houses.

Water and wind erosion are the two primary causes of land degradation; combined, they are responsible for about $84 \%$ of the global extent of degraded land, making excessive erosion one of the most significant environmental problems worldwide.

Intensive agriculture, deforestation, roads, anthropogenic climate change and urban sprawl are amongst the most significant human activities in regard to their effect on stimulating erosion.[3] However, there are many prevention and remediation practices that can curtail or limit erosion of vulnerable soils.

Fig.1 Nutrient mining causes nutrient deficiencies

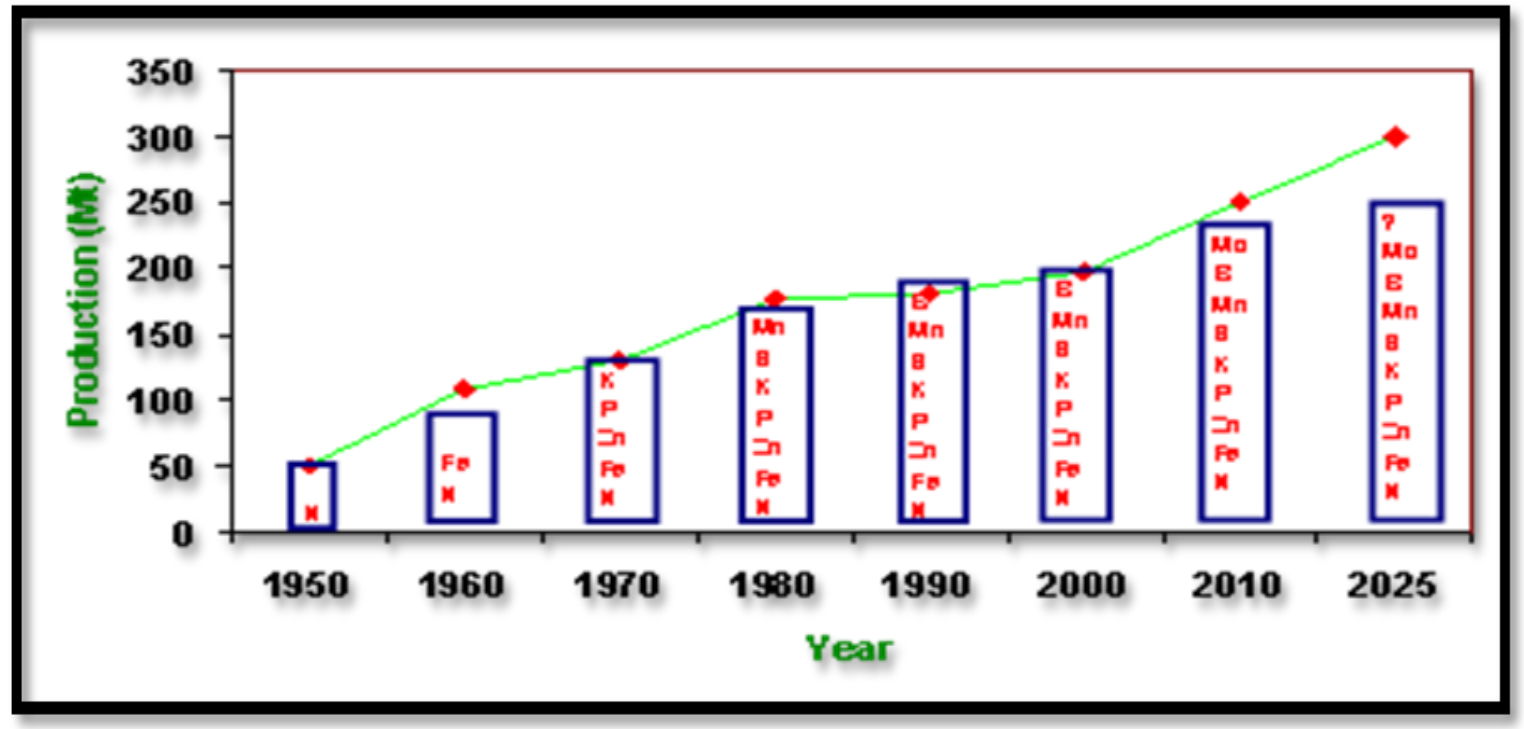


Fig.2 Nutrient mining Declining productivity

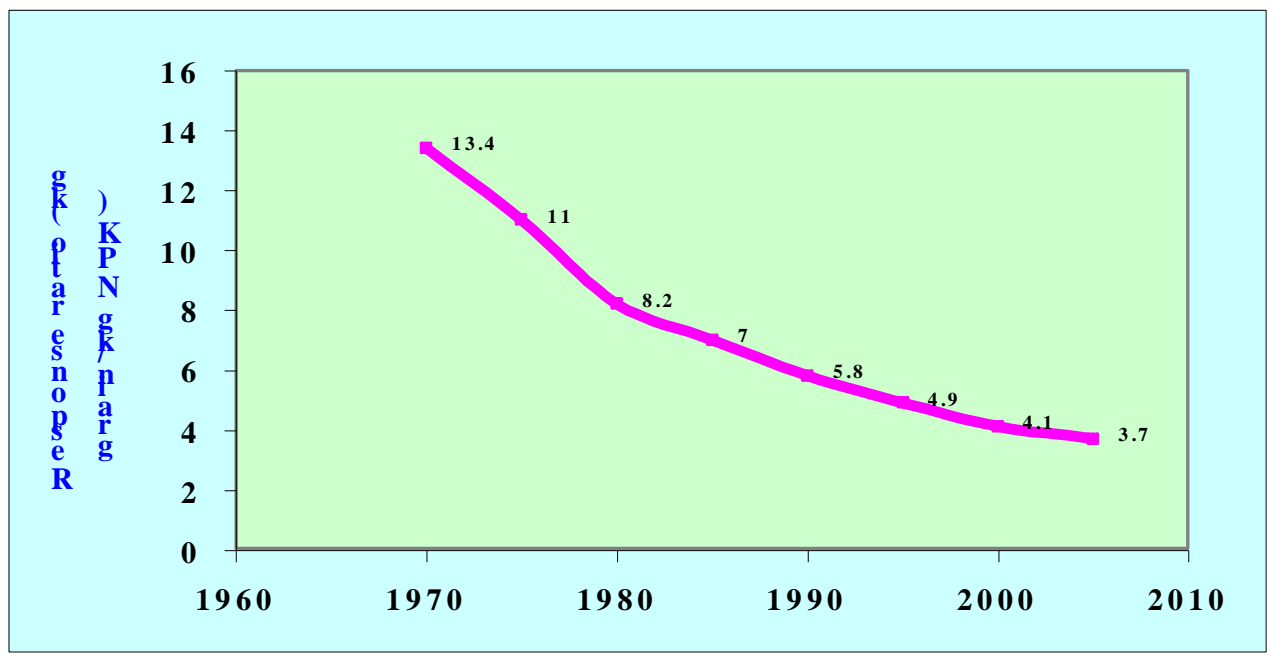

Fig.3 Nutrient inflow-outflow
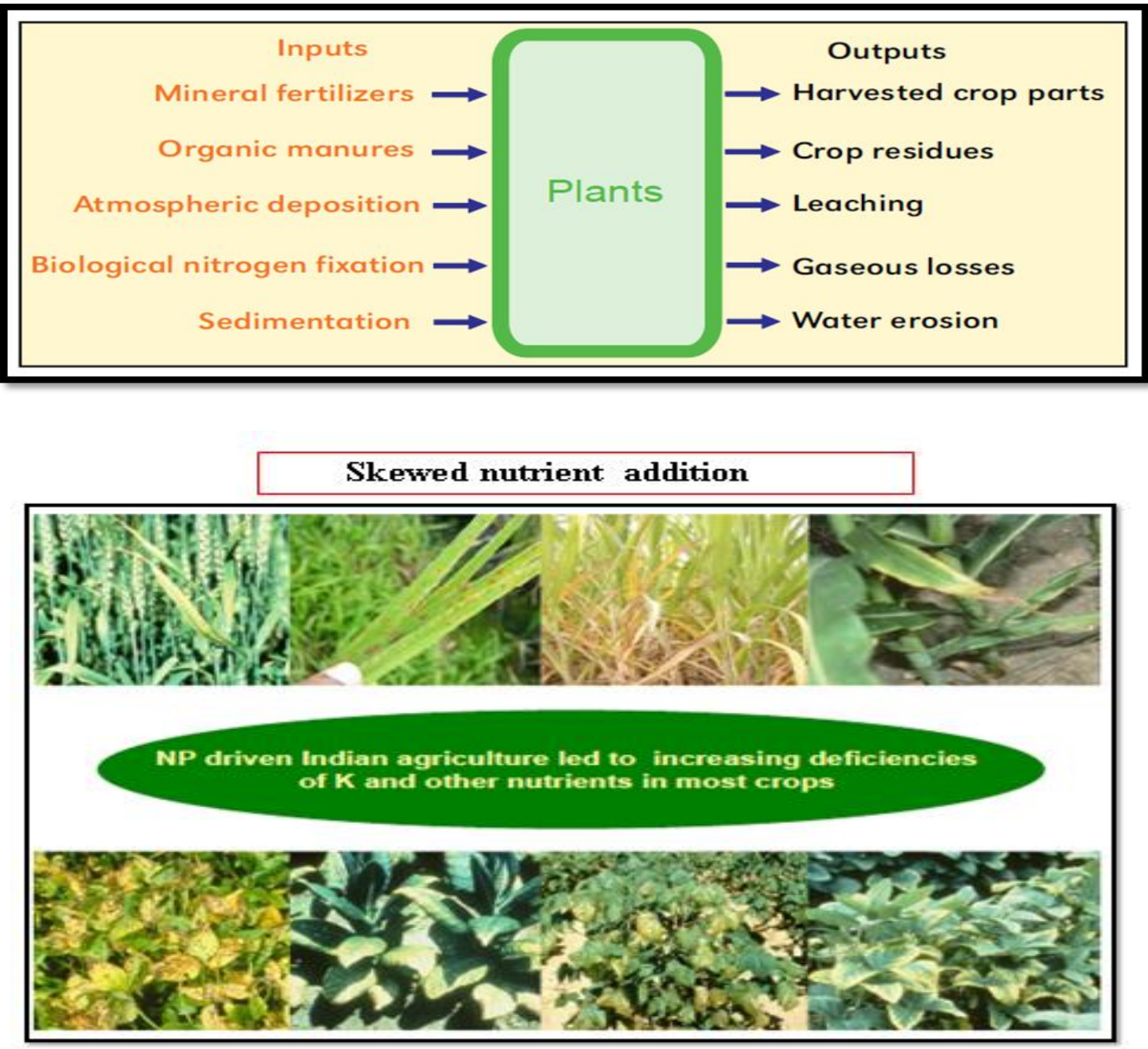
Fig.4 Nutrient addition and removal in Indian agriculture Satyanarayana (2009)

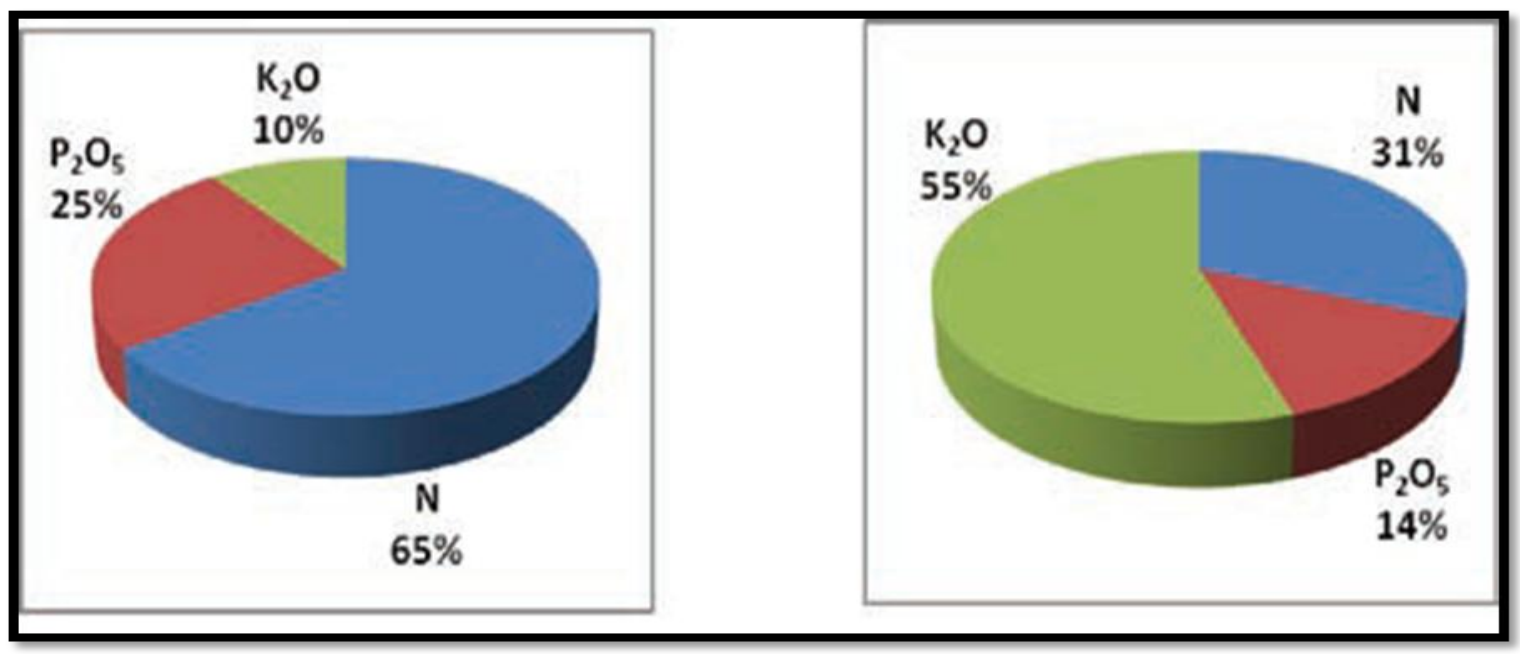

Fig.5 N balance (000t) in some agriculturally important states of India

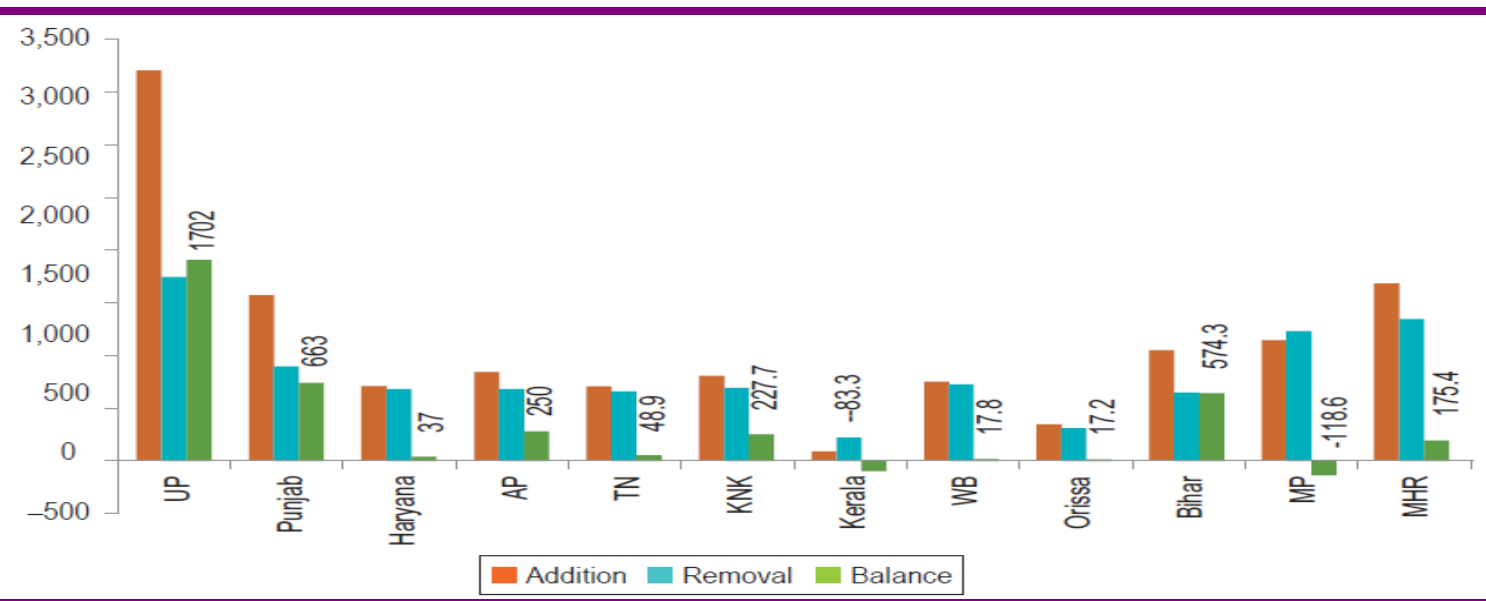

Fig.6 K balance (000t) in some agriculturally important states of India Tandon (2004)

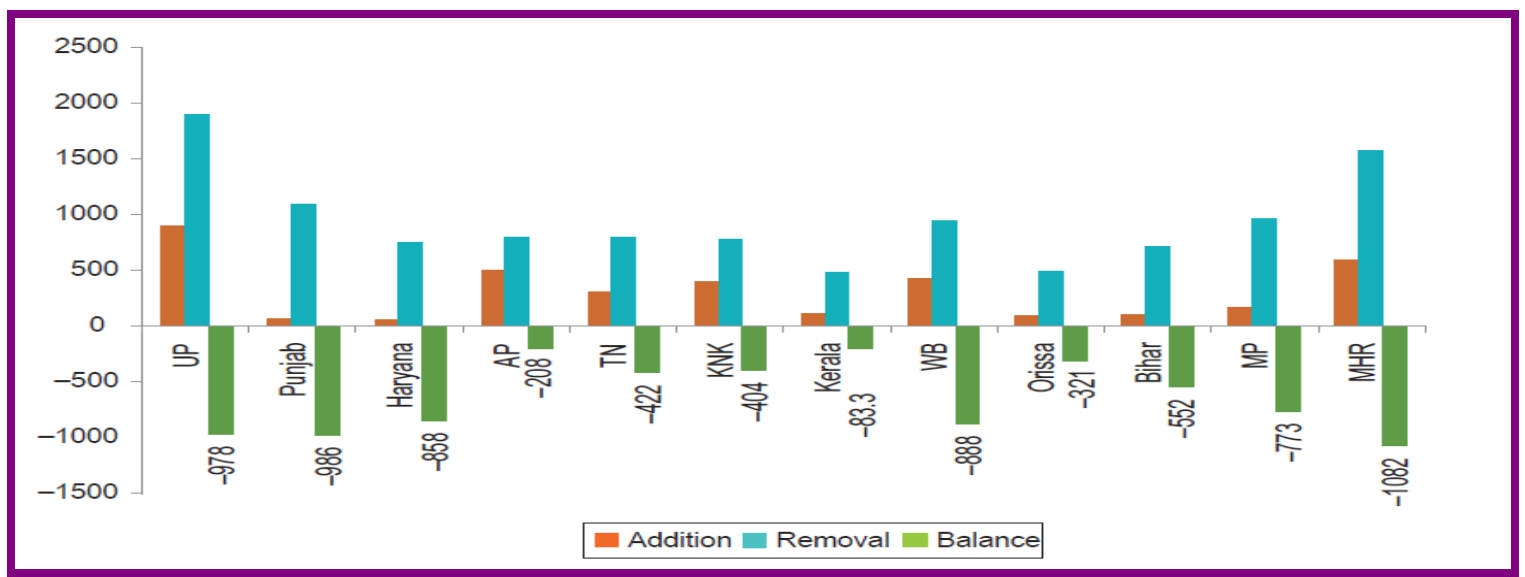




\begin{tabular}{|l|l|l|l|l|l|l|}
\hline Nutrient & \multicolumn{4}{|l|}{ Gross balance } & \multicolumn{2}{l|}{ Net balance } \\
\hline & Addition & Removal & Balance & Addition & Removal & Balance \\
\hline $\mathrm{N}$ & 10.9 & 9.6 & 1.3 & 5.5 & 7.7 & -2.2 \\
\hline $\mathrm{P}_{2} \mathrm{O}_{5}$ & 4.2 & 3.7 & 0.5 & 1.5 & 3.0 & -1.5 \\
\hline $\mathrm{K}_{2} \mathrm{O}$ & 1.4 & 11.6 & -10.2 & 1.0 & 7.0 & -6.0 \\
\hline Total & 16.5 & 24.9 & -8.4 & 8.0 & 17.7 & -9.7 \\
\hline
\end{tabular}

Fig.8 Nutrient Balance Sheet and Additional Potential of K consumption at current NPK Use in India Fertilizer statistics 2007-08

\begin{tabular}{|l|l|l|l|}
\hline Nutrient & \multicolumn{3}{|l|}{ Balance Sheet $(000 \mathrm{t})$} \\
\hline & Addition & Removal & Balance \\
\hline $\mathrm{N}$ & 5461 & 7690 & -2229 \\
\hline $\mathrm{P}_{2} \mathrm{O}_{5}$ & 1466 & 2961 & -1496 \\
\hline $\mathrm{K}_{2} \mathrm{O}$ & 1018 & 6994 & -5976 \\
\hline NPK Total & 7945 & 17645 & -9701 \\
\hline
\end{tabular}

Modelling approach

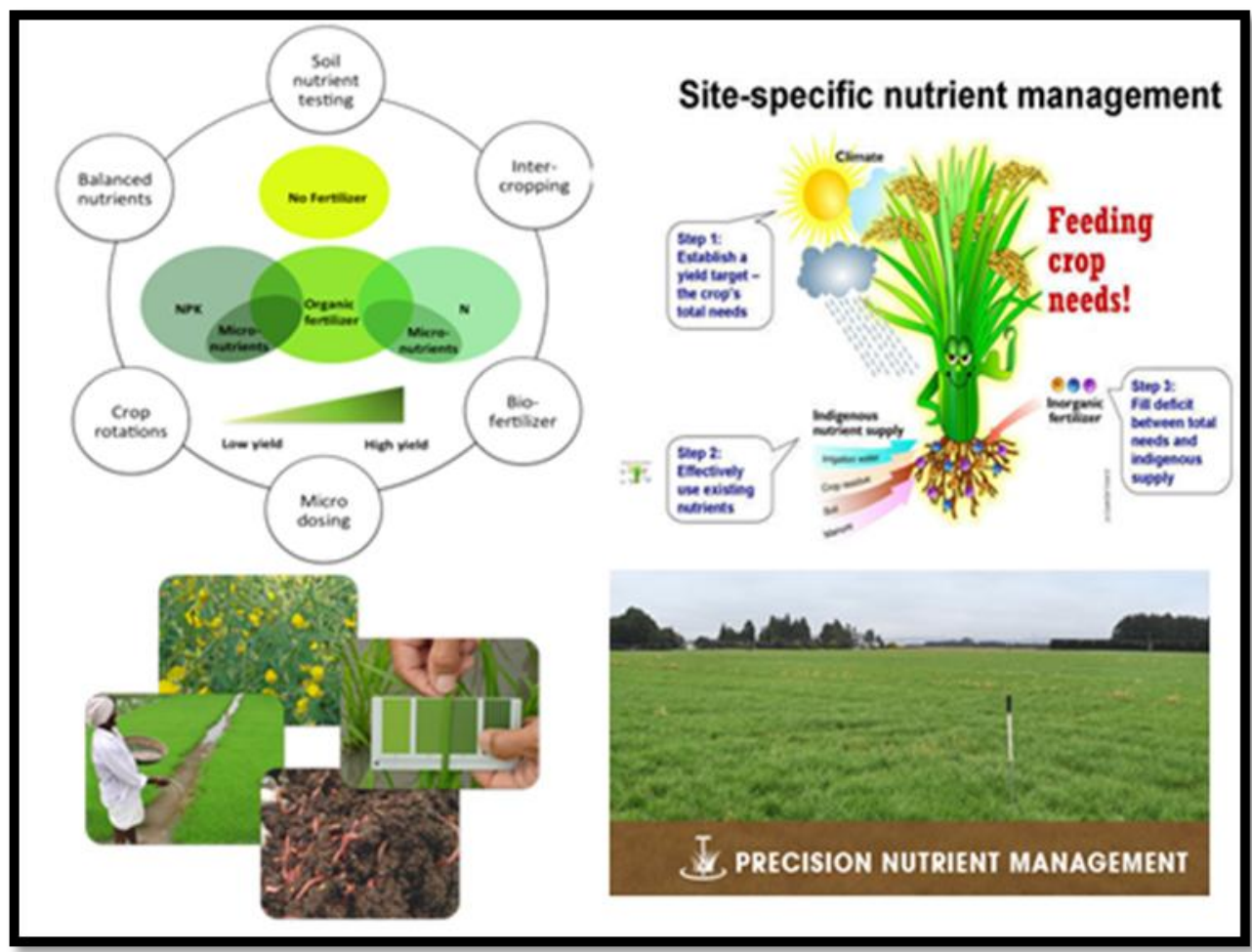




\section{Sustained nutrient management - responses}

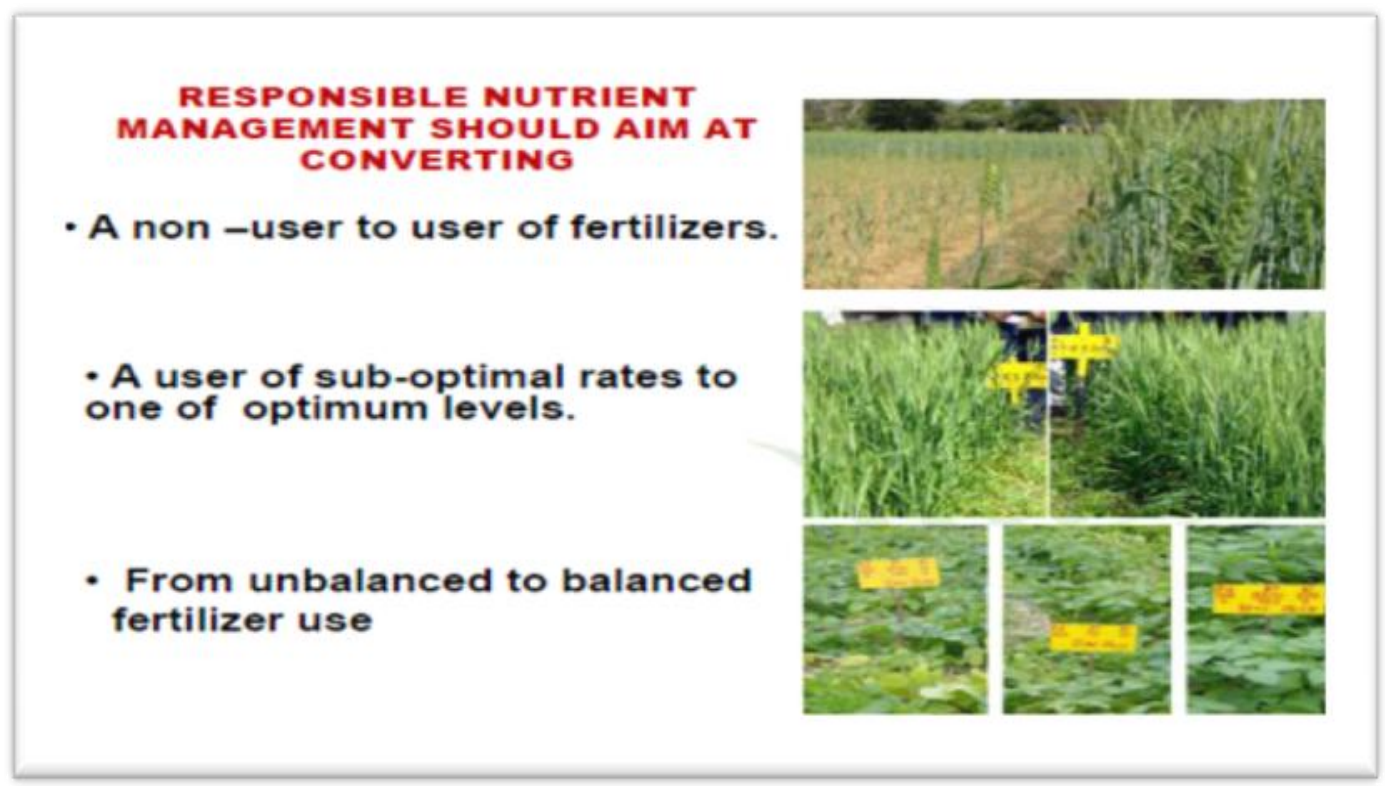

Balanced Fertilizer Application

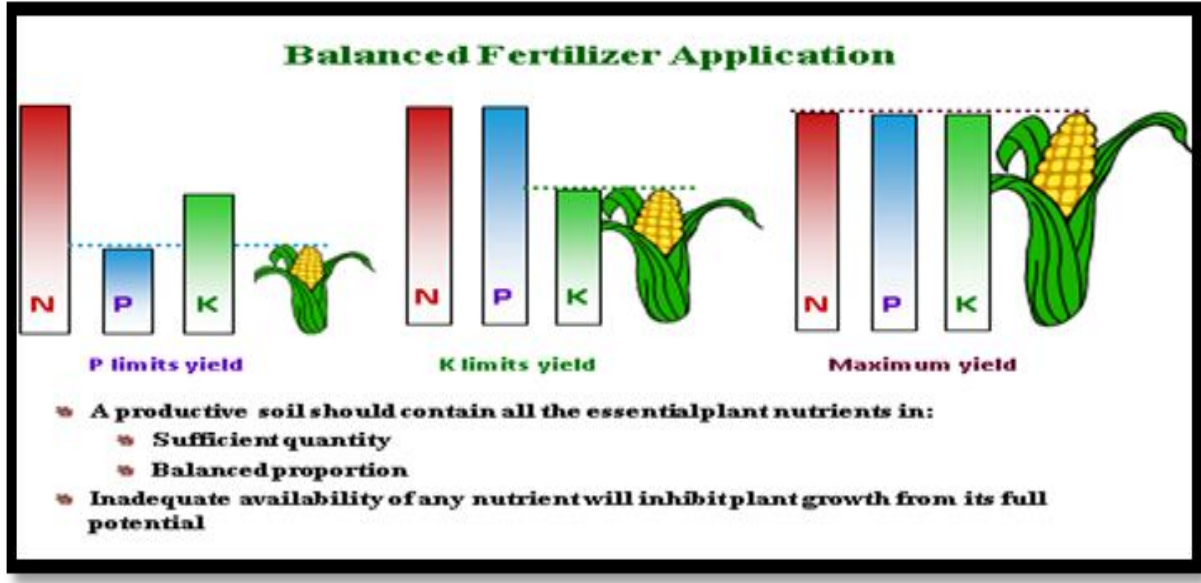

Skewed nutrient addition

It means addition of one or more nutrients in the adequate amount but application of less quantity and neglecting the addition of one more nutrient Indian agriculture is mainly driven by $\mathrm{N}$ and $\mathrm{P}$ and it leads to denitrification of $\mathrm{K}$ and other nutrients we know that farmers applies more quantity of $\mathrm{N}$ fertilizers urease and $\mathrm{P}$ for like DAP but they are neglecting the application of $\mathrm{K}$ fertilizers therefore Indian soils shows deficiency of $\mathrm{K}$.

\section{Improper nutrient ratios}

Improper nutrient ratios causes nutrient mining

\section{Nutrient losses - leaching, volatilization}

Nutrients can be lost in a number of ways. Soluble nutrients like nitrate and potassium can be lost in runoff and drainage water, whereas less soluble nutrients like phosphorus are more likely to be lost with sediments 
moving in eroding soils and run-off water. Leaching Highly soluble nutrients like nitrate and potassium are prone to leaching. Leaching occurs when the soil is saturated and can't hold any more water and drainage occurs. The drainage water dilutes and disperses the nutrients down the soil profile.

Deep rooting crops like maize can access nitrates from as deep as $180 \mathrm{~cm}$, but once nutrients are below the rooting zone, they are no longer access Volatilization of ammonia from broadcast urea happens when conditions are hot and windy.

Losses can be as high as $60 \%$ in the worst of conditions. It is often less risky to knife-in your side-dressing applications.

It means addition of one or more nutrients in the adequate amount but application of less quantity and neglecting the addition of one more nutrient Indian agriculture is mainly driven by $\mathrm{N}$ and $\mathrm{P}$ and it leads to denitrification of $\mathrm{K}$ and other nutrients we know that farmers applies $\mathrm{K}$ fertilizers therefore Indian soils shows deficiency of $\mathrm{K}$.

Farmers add more of nitrogenous fertilizers little quantity of $P$ fertilizers and very negligible amount of fertilizers.

$\mathrm{N}$ removal: The removal of $\mathrm{K}$ is more compare to addition of $\mathrm{K}$ to soil there is existence negative balance with respect to $\mathrm{K}$. Indian soils contain more of $\mathrm{K}$ very less quantity add crop requirement negative balance.

\section{Tandon (2004)}

\section{$\mathrm{N}$ - balance sheet}

Some of the agriculture states in India all the states show positive balance with respect to $\mathrm{N}$ because of addition of $\mathrm{N}$ by the farmers by huge amount even though removal is also high then also exist of positive balance with respect to $\mathrm{N}$ because addition of more nitrogen fertilizers compare to other fertilizers.
It is exactly opposite $\mathrm{N}$ balance, in all the states $\mathrm{K}$ shows the negative balance because addition of $\mathrm{K}$ is very less compare to the removal $\mathrm{K}$ from the soil there for negative balance exists in all the state of India.

Maharashtra Punjab shows high negative balance because Punjab and UP starts first and second in agriculture production therefore more mining of nutrients in Punjab and UP.

\section{Nutrient mining in soils of India (mt) Tandon (2004)}

Tandon 2004 calculated the $\mathrm{N}$ balance sheet with respect to major nutrient NPK all the major nutrient shows negative balance but among the 3 major nutrients $\mathrm{K}$ shows high negative balance compare to other nutrients this is because of neglected application of $\mathrm{K}$ by the Indian farmers.

In this graph we can clearly see that addition of nutrient is very less but removal of nutrient is more there is a gap between addition and removal of nutrients nothing but nutrient mining.

\section{Strategies to sustain soil productivity and reduce the nutrient mining}

Soil testing

INM (Integrated Nutrient Management)

Site Specific Nutrient Management

Balanced fertilizer application

Crop residues management

Use of organic matter

Management of problematic soils

Adoption of appropriate agricultural practices

4 R's (Right source, Right rate, Right time and Right method

\section{Soil testing}

Efficient use of fertilizers is a major factor in any programme designed to bring about an economic increase in agricultural production. The farmers involved in such a programme will have to use increasing quantities of fertilizers to 
achieve the desired yield levels. However the amounts and kinds of fertilizers required for the same crop vary from soil to soil, even field to field on the same soil.

The use of fertilizers without first testing the soil is like taking medicine without first consulting a physician to find out what is needed.

It is observed that the fertilizers increase yields and the farmers are aware of this. But are they applying right quantities of the right kind of fertilizers at the right time at the right place to ensure maximum profit?

Without a fertilizer recommendation based upon a soil test, a farmer may be applying too much of a little needed plant food element and too little of another element which is actually the principal factor limiting plant growth. This not only means an uneconomical use of fertilizers, but in some cases crop yields actually may be reduced because of use of the wrong kinds or amounts, or improper use of fertilizers.

\section{STCR}

In this approach soil contribution and yield levels are taken into considered for recommending fertilizer dose this approach is also called as rationalised recommendation are developed for different regions STCR approach are these equations are not available for different crops and regions and these equations suitable when available NPK estimated by potassium paramagnet, Olsen and ammonium acetate

\section{Site specific nutrient management}

Site-specific nutrient management (SSNM) is a plant-based approach for managing the nutrient requirements of rice. It provides principles and tools for supplying rice with nutrients as and when needed to achieve high yields while optimizing use of nutrients from indigenous sources.

\section{INM}

Integrated Nutrient Management refers to the maintenance of soil fertility and of plant nutrient supply at an optimum level for sustaining the desired productivity through optimization of the benefits from all possible sources of organic, inorganic and biological components in an integrated manner.

\section{Balanced fertilizer application}

Most of the Indian farmers fallow imbalance fertilizers application we need to educate the farmers to overcome the nutrient mining.

\section{Crop residue management}

Use of organics, compost, green manure these adds adequate quantity we can manage the nutrient mining

\section{Management of problematic soils}

Acidic soil amendment with lime, saline and alkaline soil gypsum $\mathrm{pH}$ tend to neutral as the nutrients available to soil.

\section{R's (Right source, Right rate, Right time and Right method}

Precision agriculture (PA) or satellite farming or site specific crop management (SSCM) is a farming management concept based on observing, measuring and responding to inter and intra-field variability in crops. The goal of precision agriculture research is to define a decision support system (DSS) for whole farm management with the goal of optimizing returns on inputs while preserving resources

\section{DRIS}

Diagnosis recommendation integration system nutrient ratios in plants are considered for fertilizer recommendations. Plant samples are analysed for nutrient content this approach mainly for soybean and wheat. 


\section{Modelling approach}

Suitable for recommendation of nitrogenous fertilizers where soils are rich in organic matter as in temperature region

\section{Critical limits}

They are arrived for different nutrients for different soils, crops and regions based on pot culture studies this approach is being fallowed for $\mathrm{P}$ and most of the micronutrient

\section{LCC}

$\mathrm{N}$ fertilizers are recommended based on leaf colour of rice top dressing of $\mathrm{N}$ to rice based on leaf colour chart is advantageous over top dressing at 20 and 40 days after transplanting

To overcome the nutrient mining these are the some of the sustainable nutrient management practices.

In India there are 3 categories of farmers:

Non user of fertilizers

Those who use the fertilizers at sub -optimal rates

Some of the farmers fallow un balanced to balanced

So we need to educate the farmers to use the fertilizers and one who use the optimal rate we need to educate them to fallow optimum level and one who fallow unbalanced educate balanced application is very essential to overcome the nutrient management

\section{Balanced fertilizer application}

Balanced fertilizer application is very essential in figure $\mathrm{N}$ and $\mathrm{K}$ is good enough but very little quantity of $\mathrm{P}$ which limits the growth and yield of the crop.

In second figure $\mathrm{N}$ and $\mathrm{P}$ are good enough very little quantity of $\mathrm{K}$ limits the growth and yield of crop. Balanced application of nutrient NPK optimum level we can get good yield.

\section{References}

Ramachandrappa, B. K., Sathish, A., Dhanapal, G. N., Balakrishna Reddy, P. C., Shankar, M. A. and Srikanth Babu, P. N., 2014, Potassium nutrition on yield and economics of rainfed finger millet in eastern dry zone of Karnataka. Indian J. Soil Cons., 2(42): 188- 195.

Sanyal, S, K., Majumdar, K. and Singh, V. K., 2014, Nutrient management in Indian agriculture with special reference to nutrient mining, J. Indian Soc. Soil Sci., 62(4): 307-325.

SatyaNaryana, M. and Surya Prabha, A. C., 2009, Studies on nutrient uptake, post harvest nutrient availability and nutrient balance sheet under integrated nutrient management practice in wet seeded rice. Asian J. Soil Sci., 2(1): 33-39.

Subbarao and Srivastav, G.K., Debnath, A., Chattopadhyay, A.P. and Sanyal, S.K. 2007 Depletion of soil potassium under exhaustive cropping in Inceptisol and Alfisols. Communications in Soil Science and Plant Analysis 45, 61-72.

Tandon, H.L.S. (2007) Soil nutrient balance sheets in India: Importance, status, issues, and concerns. Better Crops India1, Pp. 15-19.

\section{How to cite this article:}

Mamathashree, C.M., S.M. Shilpha and Pradeep. 2017. Nutrient Mining by Selected Cereal Crops and Strategies to Sustain Soil Productivitey. Int.J.Curr.Microbiol.App.Sci. 6(12): 2932-2941. doi: https://doi.org/10.20546/ijcmas.2017.612.341 